Conclusion A multidisciplinary approach to the ongoing management of HPN patients can dramatically reduce their risk of CBSI

\section{PROSPECTIVE STUDY OF CENTRAL VENOUS CATHETER INFECTIONS IN CRITICALLY ILL CHILDREN AT A REGIONAL PAEDIATRIC INTENSIVE CARE UNIT}

doi:10.1136/archdischild-2012-302724.0581

H Gowda, C Penrose. Paediatric Intensive Care Unit, Leeds Teaching Hospitals NHS Trust, Leeds, UK

Background and Aims Central venous catheters (CVC) play an important role in the management of critically ill children, serving both as a reliable vascular access and site of venous pressure monitoring.

To find the incidence CVC related infection and risk factors associated with these complications from different central venous access sites in critically ill children.

Methods A prospective study (August 2010 to July 2011) of 227 central venous catheterisations in children of different ages in a large regional Paediatric Intensive Care Unit. Data on demography, site of insertion and type of CVC infections were collected.

Results Total number of CVC days (for 227 CVC) was 960 days.

Abstract 581 Table 1 CVC infections

\begin{tabular}{lcccc}
\hline $\begin{array}{l}\text { Category of CVC } \\
\text { infection }\end{array}$ & $\begin{array}{c}\text { Catheter related Clinical suspicion of } \\
\text { bacteremia }\end{array}$ & $\begin{array}{c}\text { Local } \\
\text { catheter infection }\end{array}$ & $\begin{array}{c}\text { Catheter } \\
\text { infection }\end{array}$ \\
\hline colonisation \\
\hline pumber of cases & 7 & 14 & 1 & 11 \\
\hline
\end{tabular}

Abstract 581 Table 2 Catheter related bacteremia

\begin{tabular}{lc}
\hline Type of bacteria & Number of cases \\
\hline Coagulase negative staphylococcus & $4 / 7$ \\
Staphylococcus aureus & $2 / 7$ \\
Escherichia coli & $1 / 7$ \\
\hline
\end{tabular}

Abstract 581 Table 3 Internal jugular vein vs femoral vein

\begin{tabular}{|c|c|c|}
\hline & Internal jugular vein & Femoral vein \\
\hline CVC infection & $11 / 127(8.66 \%)$ & $11 / 90(12.22 \%)$ \\
\hline Catheter related bacteremia & $3 / 11$ & $4 / 11$ \\
\hline
\end{tabular}

Relative risk (RR) for femoral vein vs internal jugular vein for CVC infections is 1.4 .

Conclusion Incidence of catheter related bacteremia was 7.29 per 1000 catheter days. Femoral lines have marginal higher infections compared to internal jugular lines.

\section{RISK FACTORS FOR CENTRAL-LINE ASSOCIATED BLOODSTREAM INFECTIONS IN CRITICALLY ILL NEONATES}

doi:10.1136/archdischild-2012-302724.0582

M Pavcnik-Arnol, G Kalan. Department of Pediatric Surgery and Intensive Care, University Medical Centre Ljubljana, Ljubljana, Slovenia

Background and Aims The improvement of central line insertion and maintenance practices has led to reduction but not elimination of central line-associated bloodstream infections (CLABSIs) in critically ill neonates. The objective of our study was to describe CLABSI epidemiology in critically ill neonates in order to identify risk factors for additional prevention strategies.

Methods Prospective cohort study in medical-surgical neonatal and pediatric ICU. All neonates admitted between January 1, 2011, and January 31, 2012 with $\geq 1$ central lines were monitored for the development of CLABSI. Risk factors for CLABSI were examined.

Results Nine CLABSIs occurred during 1640 central line-days (5.5/1000 central line-days). Seven out of 9 CLABSIs (78\%) occurred in neonates with primary surgical diagnosis (gastrointestinal tract anomaly 4, congenital heart disease 2 , rabdomyosarcoma 1), two CLABSIs developed in neonates with hypoxic-ischemic encephalopathy. Neonates with CLABSI had significantly longer ICU length of stay compared to other neonates requiring central line (median 27 vs. 3 days; $p<0.0001$ ), higher PRISM III score (median 14.5 vs. 7; $\mathrm{p}=0.01$ ), more surgical procedures (median 2 vs. $1 ; \mathrm{p}=0.14$ ), longer duration of parenteral nutrition (median 10 vs. 0 days; $p<0.0001$ ), received more red blood cell transfusions (median 5 vs. $0 ; p<0.0001$ ), needed more vasopressor/inotropic agents (median 2 vs. $0 ; p=0.002$ ). Conclusion The incidence of CLABSI is significantly higher in neonates with primary surgical diagnosis (particularly gastrointestinal tract anomaly) and with hypoxic-ischemic encephalopathy compared to other neonates requiring a central line. The increased risk of CLABSI in these neonates warrants further study for development of additional prevention strategies.

\section{THREE YEAR SURVEY OF BLOOD STREAM INFECTIONS (BSI) IN A PAEDIATRIC INTENSIVE CARE UNIT (PICU)}

doi:10.1136/archdischild-2012-302724.0583

'A Gupta, ${ }^{1} \mathrm{~A}$ Top, ${ }^{2} \mathrm{M}$ Farrington. ${ }^{1}$ Paediatric Intensive Care Unit; ${ }^{2}$ Microbiology, Addenbrookes Hospital, Cambridge, UK

Background and Aims Nosocomial infection is a common cause of morbidity and mortality in PICU. Timely microbiological surveillance and assessment of antimicrobial resistance is important in treatment. We studied the microbiological spectrum and susceptibility pattern of pathogens in PICU over 3 years.

Methods Results of blood cultures and antimicrobial susceptibility were reviewed retrospectively over a three year period (April 2008 to 2011). The incidence of nosocomial infections and associated pathogens was analyzed. Positive blood cultures after 48hours of admission were considered as nosocomial BSI.

Results There were 1653 PICU admissions of which 836 patients stayed for more than 48 hours. Overall incidence of BSI was 3.6\% (60 episodes in 1653 patients). Incidence of nosocomial BSI was $2.9 \%$ (24 episodes in 836 patients).

During first 48 hours there were 36 positive blood cultures, 24 Gram-positive (67\%) and 12 Gram-negative (33\%). After 48 hours, there were 24 positive cultures, 20 Gram-positive (83\%) and 4 Gram-negative (17\%). Coagulase negative staphylococcus was the commonest isolate (13/24 nosocomial infections). Other nosocomial pathogens were Staphylococcus aureus $(n=4)$, Enterococus ( $\mathrm{n}=3)$, E. coli, Klebsiella, Pseudomonas and Acinetobacter (1 each).

Varying degree of resistance observed to first line antibiotics (penicillin, gentamicin, 3rd generation cephalosporins). No resistance to second and third line antibiotics (vancomycin, meropenem and tazocin).

Conclusions Gram positive organisms are the predominant cause of nosocomial infections in this study. No multiresistant organisms isolated. However, judicious use of antibiotics is important to prevent emergence of multiresistant strains.

\section{CATHETER ASSOCIATED BLOOD STREAM INFECTION IN PEDIATRIC INTENSIVE CARE}

doi:10.1136/archdischild-2012-302724.0584

${ }^{1} \mathrm{E}$ İnce, ${ }^{2} \mathrm{~T}$ Kendirlii, ${ }^{3} \mathrm{~A}$ Yaman, ${ }^{3} \mathrm{C}$ Ödek, ${ }^{4} \mathrm{~A}$ Karbuz, ${ }^{5} \mathrm{~B}$ Aldemir, ${ }^{4} \mathrm{H}$ Özdemir, ${ }^{4} \mathrm{E}$ Çiftçi, ${ }^{6} \mathrm{H}$ Güriz, ${ }^{6} \mathrm{D}$ Aysev. ${ }^{1}$ Pediatric Infectious Disease; ${ }^{2}$ Pediatric ICU, Ankara University, Faculty of Medicine; ${ }^{3}$ Pediatric ICU; ${ }^{4}$ Pediatric Infectious Disease, Ankara University, Ankara; ${ }^{5}$ Pediatric Infectious Disease, Ankara University, Adana; ${ }^{6}$ Microbiology Laboratory, Ankara University, Ankara, Turkey 